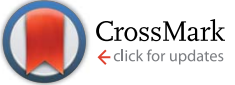

Cite this: RSC Adv., 2017, 7, 10070

Received 14th November 2016 Accepted 27th January 2017

DOI: $10.1039 / \mathrm{c} 6 \mathrm{ra2} 6779 \mathrm{c}$

rsc.li/rsc-advances

\title{
Conformational stabilization of isatin Schiff bases - biologically active chemical probes $\uparrow$
}

\author{
Andrey S. Smirnov, ${ }^{\text {ab }}$ Dmitriy N. Nikolaev, ${ }^{c}$ Vlad V. Gurzhiy, ${ }^{b}$ Sergey N. Smirnov, ${ }^{b}$ \\ Vitaliy S. Suslonov, ${ }^{b}$ Alexander V. Garabadzhiu ${ }^{a}$ and Pavel B. Davidovich*a
}

\begin{abstract}
Isatin Schiff base derivatives have a wide range of biological effects. Unfortunately, these compounds possess a serious topological shortcoming: the conformational $E \leftrightarrows Z$ interconversion. Two ways of conformation stabilization are reported here: complexation with metals that stabilize the $E$-conformer and substitution in the $4^{\text {th }}$ position of the isatin core stabilizing the $Z$-form.
\end{abstract}

Isatin ${ }^{1}$ is a naturally occurring alkaloid first discovered in plant species and later found as a blood circulation molecule that can easily cross the blood-brain barrier acting as an endogenous neurotransmitter activator. ${ }^{3}$ To date it is known that isatin and its analogues have a plethora of biological effects ${ }^{4}$ including antitumor activities. ${ }^{5}$ Modified by hyrdoxamic acids, isatin-3oxymes are potent for T-cell lymphoma killing, acting as a micromolar histone deacetylase inhibitors. ${ }^{6}$ It was shown on a cellular leukemia model that $N$-substituted acrylate isatin derivatives promote cell cycle arrest and apoptosis induction. ${ }^{7}$ Isatin- $\beta$-thiosemicarbazones show selective proliferation inhibition towards multidrug-resistant cell lines. ${ }^{8}$ 5-Sulfonamide and -aryl substituted isatins act as inhibitors of cancer associated matrix metalloproteinases. ${ }^{9,10}$ Isatin Schiff bases with benzenesulfonamide moiety have been recently identified as tumor associated carbonic anhydrase IX and XII inhibitors. ${ }^{11}$ Our previous work ${ }^{12}$ showed that isatin Schiff base derivatives (ISBDs) activate p53 transcription factor - the major oncosuppressor protein. Unfortunately, ISBDs poses a serious drawback - intramolecular isomeric interconversion. Since $E$ and $Z$ isomers significantly differ topologically, one becomes almost an impurity that may cause undesirable side effects. $E \leftrightarrows Z$ equilibrium occurs in most of the solvents (the ratio is slightly dependent on the solvent ${ }^{14}$ ) with preferable $E$-conformation, which makes circa $80-90 \% .{ }^{13}$ It is recognized that indole like scaffolds are privileged in medicinal chemistry molecule space, ${ }^{15}$ thus making ISBDs more conformationally rigid is an important and actual objective.

\footnotetext{
${ }^{a}$ Saint-Petersburg Technological Institute, Moskovskii av. 26, St. Petersburg, 190013, Russia.E-mail: davidovich.pavel@technolog.edu.ru

${ }^{b}$ Saint-Petersburg State University, University emb. 7/9, St. Petersburg, 199034, Russia 'Research Institute of Experimental Medicine, Akad. Pavlova str. 12, St. Petersburg, 197376, Russia

$\dagger$ Electronic supplementary information (ESI) available: Experimental, crystallographic details, NMR and MS details. CCDC 1505866-1505870 and 1506944. For ESI and crystallographic data in CIF or other electronic format see DOI: $10.1039 / \mathrm{c} 6 \mathrm{ra} 26779 \mathrm{c}$
}

This report is a proof-of-principle that shows how conformational interconversion may be stopped by applying two different approaches: substitution in the isatin aromatic moiety (ring A on Fig. 1) and complexation with d-metals. These data are supported by the structural X-ray solid state and NMR solution studies that are accompanied by DFT calculations. It is worth noting, that the structural findings in coordination chemistry of isatin-aromatic amines Schiff bases up-to-date remain scarce and are limited to one work describing homoleptic bischelate copper(II) complex with isatin-4-hexylaniline. ${ }^{16}$

To study the metal complexation processes we have prepared the model compound - 1-methyl-3(phenylimino)indolinone-2one (I) by the method described in our previous paper. ${ }^{14}$ As non-protected amide nitrogen $(\mathrm{NH})$ is acidic enough to form contacts with d-metals, this potential reactive center was blocked by $N$-methylation.

XRD study showed that ISBD I adopts only $E$-conformation outlined in Fig. 2§:

In solution interconversion results in methyl proton peak signal splitting and the $E / Z$ ratio can be estimated as a peak surface relation. Solution phase NMR data (Fig. 2B) shows that $10: 1 E$ - to $Z$-conformer ratio is settled in $\mathrm{CDCl}_{3}$ for ISBD $\mathbf{I}$.

We have expected that introduction of substituent in the $4^{\text {th }}$ position (Fig. 1) can force the molecule to adopt $Z$-conformation, as a reason of steric repulsion between substituent and aromatic ring C. Using CAM-B3LYP functional that includes long-range corrections, total energy differences $\left(\Delta E_{\text {tot }}=E_{Z}-E_{E}\right.$, $\mathrm{kJ} \mathrm{mol}^{-1}$, for $\mathrm{R}_{4}=\mathrm{H}, \Delta E_{\text {tot }}=0$ ) between two conformers with various substituents in ring A were estimated. For the most common isatin derivatives $\Delta E_{\text {tot }}$ changes in the following order: $\mathrm{H}(0), \mathrm{Me}(-23.5), \mathrm{CF}_{3}(-30.0)$, Et (-28.3), OMe (-6.2), F (-5.4), $\mathrm{Cl}(-19.4), \mathrm{Br}(-23.5)$, CN (-24.5). Hence using methyl substituent should be enough to make the molecule adopt

$\S$ Here and further atoms are drawn in thermal ellipsoids at $50 \%$ probability level and hydrogens are omitted for clarity. Of note, compound I polymorph was earlier described. ${ }^{2}$ 


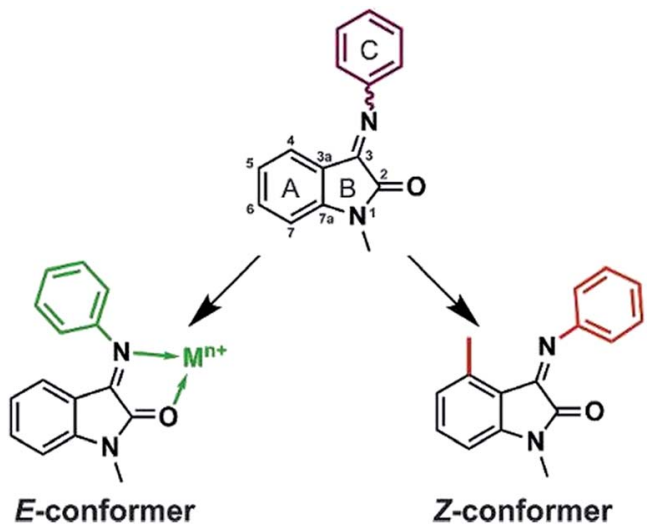

Fig. 1 Two principal ways to fix phenyl ring orientation: by complexation with metals and substitution in isatin core.

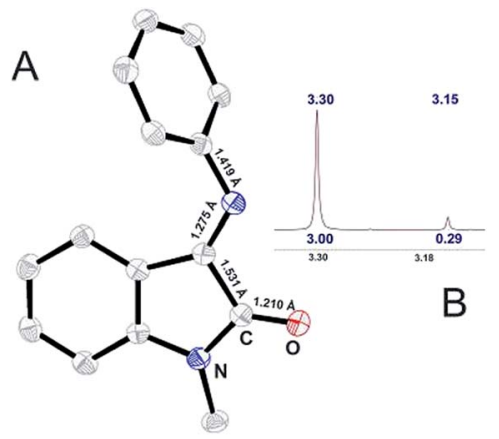

Fig. 2 (A) ORTEP representation of $X$-ray determined molecular structure of I and (B) ${ }^{1} \mathrm{H}$ NMR signal for $N$-methyl group of $\mathrm{I}$.

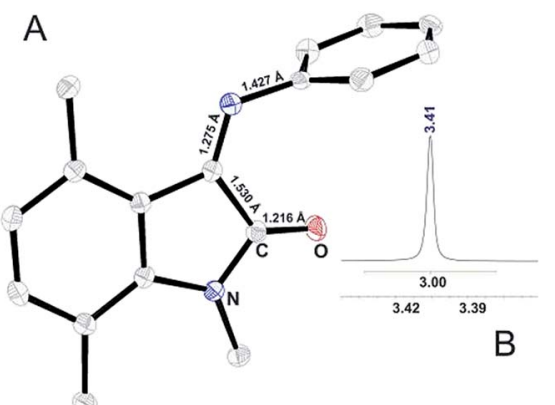

Fig. 3 (A) ORTEP representation of $X$-ray determined molecular structure of II and (B) ${ }^{1} \mathrm{H}$ NMR signal for $\mathrm{N}$-methyl group of II.

$Z$-conformation. Staring from these assumptions, we have prepared 1,4,7-methylated ISBD with ring $\mathrm{C}$ represented by 2,6diisopropylaniline (III, Fig. S2 $\dagger$ ) and aniline (II, Fig. 3):

As depicted in Fig. 3, introduction of methyl group in the $4^{\text {th }}$ position results in the crystallization of compound II $Z$ conformer. Up to date it is the first crystallized ISBD in $Z$ conformation. The absence of methyl signal splitting in ${ }^{1} \mathrm{H}$ NMR spectrum (Fig. 3B) confirms that no interconversion occurs in solution. Thus, it can be stated that substitution in the isatin core can be used as a strategy to stabilize $Z$-form of ISBD and may be further applied for medicinal chemistry purposes.
Ligand flexibility reduction by metal complexation has long been known, but practical aspects of this effect remain limited. To validate hypothesis of ISBDs $E$-conformation stabilization by complexation with metals we have performed ligand I reactions with diamagnetic metal ions. Attempts to isolate complexes with RedOx stable biogenic diamagnetic earth metals and zinc salts were in vain. This could be the reason of noncomplementarity between a soft base (ligand) and hard $\mathrm{M}(\mathrm{II})^{17}$ acids. Attempt to get the complex with $\mathrm{Mg}$ (II) ions resulted in formation of low melting point (110-112 ${ }^{\circ} \mathrm{C}$ ) crystals (IV, Fig. $1 \mathrm{~S} \dagger$ ) consisting of an equimolar ratio of both Schiff base and its hydrolyzed product - N-methyl-isatin. Therefore, it might be expected that coordination with some metals can induce nucleophilic attack of hydroxide anion $\left({ }^{-} \mathrm{OH}\right)$ on $\mathrm{C} 3$ atom attenuating labile azomethine $\mathrm{C}=\mathrm{N}$ bond promoting its hydrolytic cleavage. This assumption can be supported by Ghosh works, ${ }^{18,19}$ where the authors reported $\mathrm{C}=\mathrm{N}$ bond cleavage of benzoquinone ligand promoted by coordination to $\mathrm{Rh}(\mathrm{III})$ ions.

We have managed to isolate and structurally characterize two novel complexes with softer $\mathrm{Cd}(\mathrm{II})$ and $\mathrm{Hg}$ (II) acids. The complexes were prepared by the reaction of ligand double excess with $\mathrm{HgBr}_{2} / \mathrm{CdBr}_{2}$ salts dissolved in ethanol. The reaction resulted in isolation of crystalline coordination products as well as unreacted ligand. Upon coordination to $\mathrm{Hg}$ (II) ion carbonyl frequency shifts from $1734 \mathrm{~cm}^{-1}$ lower to $1708 \mathrm{~cm}^{-1}$, while the $\mathrm{C}=\mathrm{N}$ vibration slightly moves from $1604 \mathrm{~cm}^{-1}$ to $1606 \mathrm{~cm}^{-1}$. The Cd(II) complex carbonyl vibration exhibits shift towards $1707 \mathrm{~cm}^{-1}$, while the $\mathrm{C}=\mathrm{N}$ vibration remains almost unaffected $1608 \mathrm{~cm}^{-1}$ (Fig. 4):

Obtained Cd(II) complex was insoluble in almost all widely used solvents, what resulted in NMR experiment failure. Nonetheless, the MS analysis of Cd(II) complex in DMSO/MeOH mixture showed the predominant peak attributed to monochelate $[\mathrm{Cd}(\mathrm{L}) \mathrm{Br}]^{+}(M / Z=428.92)$ complex with the minor peak corresponding to bischelate $\left[\mathrm{Cd}(\mathrm{L})_{2} \mathrm{Br}\right]^{+}$(Fig. S18, $\uparrow M / Z=$ 665.02) species.

The negligible solubility turned to be the issue of the polymeric crystal structure. $\$$ It is seen in the figure below that $\mathrm{Cd}(\mathrm{II})$ ions form monochelate complex with ISBD I and are bridged by two bromide anions forming infinite chain with mean Cd to Cd distance of $\sim 3.95 \AA$ (Fig. 5).

$\ddagger$ Crystal structures of I-VI were determined by the means of single crystal X-ray diffraction analysis using a Rigaku Oxford Diffraction Supernova Atlas (I, IV and VI) and an Excalibur Eos (II, III and V) diffractometers at a temperature of 100 K. I: $\left(\mathrm{C}_{15} \mathrm{H}_{12} \mathrm{~N}_{2} \mathrm{O}\right), P 2_{1} / c, a=9.4554(3), b=11.8767(3), c=10.4401(2) \AA, \beta=$ 91.739(2) $, V=1171.88(5) \AA^{3}, Z=4, R_{1}=0.037$, CCDC 1505866. II: $\left(\mathrm{C}_{17} \mathrm{H}_{16} \mathrm{~N}_{2} \mathrm{O}\right), P 2_{1} / c, a=10.2483(3), b=8.1749(2), c=16.2529(6) \AA, \beta=$ 102.182(3) $)^{\circ}, V=1330.99(8) \AA^{3}, Z=4, R_{1}=0.038$, CCDC 1505868. III: $\left(\mathrm{C}_{23} \mathrm{H}_{28} \mathrm{~N}_{2} \mathrm{O}\right), P 2{ }_{1} / c, a=8.5182(6), b=29.4795(14), c=8.4782(5) \AA ̊ ., \beta=$ 115.150(8) ${ }^{\circ}, V=1927.1(2) \AA^{3}, Z=4, R_{1}=0.047$, CCDC 1505867. IV: $\left(\mathrm{C}_{15} \mathrm{H}_{12} \mathrm{~N}_{2} \mathrm{O}\right) \cdot\left(\mathrm{C}_{9} \mathrm{H}_{7} \mathrm{NO}_{2}\right), P \overline{1}, a=7.8377(2), b=8.33995(19), c=31.7116(6) \AA$, $\alpha=85.8492(17)^{\circ}, \beta=85.7112(18)^{\circ}, \gamma=69.989(2)^{\circ}, V=1939.83(8) \AA^{3}, Z=4, R_{1}$ $=0.061$, CCDC 1505870. V: $0.5\left(\mathrm{C}_{30} \mathrm{H}_{24} \mathrm{Br}_{4} \mathrm{Cd}_{2} \mathrm{~N}_{4} \mathrm{O}_{2}\right), P \overline{1}, a=7.2618(3), b=$ 11.2036(10), $c=20.2141(11) \AA, \alpha=93.876(6)^{\circ}, \beta=98.487(4)^{\circ}, \gamma=107.037(6)^{\circ}$, $V=1544.4(8) \AA^{3}, Z=4, R_{1}=0.069$, CCDC 1506944. VI: $\left(\mathrm{C}_{30} \mathrm{H}_{24} \mathrm{Br}_{4} \mathrm{Hg}_{2} \mathrm{~N}_{4} \mathrm{O}_{2}\right)$, $P 2_{1} / c, a=23.6723(11), b=19.9737(5), c=14.0418(4) \AA, \beta=101.024(3)^{\circ}, V=$ 6516.8(4) $\AA^{3}, Z=8, R_{1}=0.068, \operatorname{CCDC} 1505869$. 


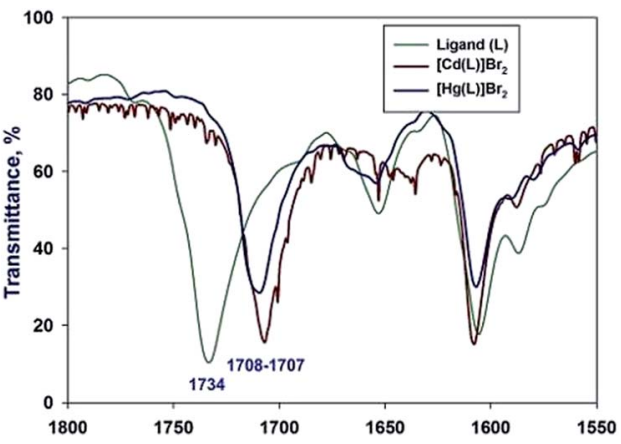

Fig. 4 Superimposition of IR spectra for I, V and VI.

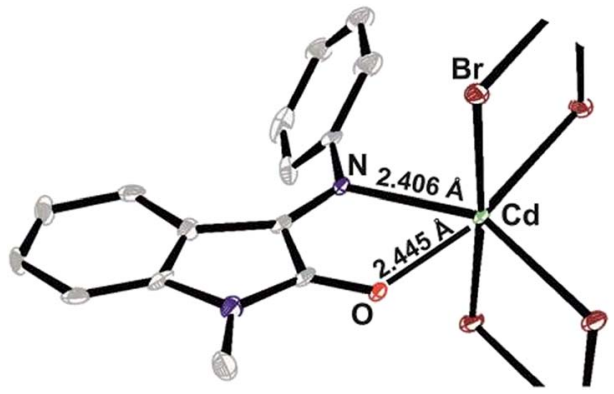

Fig. 5 ORTEP plot of $\mathrm{X}$-ray determined structure of $\mathrm{V}$ (coordination polymer).

By the analogy with $\mathrm{Cd}(\mathrm{II})$, coordination of $\mathbf{I}$ to $\mathrm{Hg}$ (II) ions resulted in the $N, O$-monochelate complex formation $[\mathrm{M}(\mathrm{L})] \mathrm{Br}_{2}$ (Fig. S19, $\dagger M / Z=516.98)$. The bischelate complex $\left[\mathrm{Hg}(\mathrm{L})_{2}\right] \mathrm{Br}_{2}$ was also detected by MS method, but in a less extent (Fig. S19, $\dagger$ $M / Z=735.07)$. We have isolated a monocrystalline sample and characterized the molecular structure of monochelate complex $[\mathrm{Hg}(\mathrm{L})] \mathrm{Br}_{2}$ (VI) 9 that is outlined in Fig. 6A:

The cell unit of VI is formed by the several types of slightly different elemental fragments of the monochelate mercury(II) complex (unequal $\mathrm{Hg}-\mathrm{N}$ and $\mathrm{Hg}-\mathrm{O}$ bond lengths). The weak interactions between $\mathrm{Hg}^{2+}$ cation and $\mathrm{Br}^{-}$anions of the neighboring molecules might be the reason of such inequalities (Fig. 7):

The solution study of $\left[\mathrm{Hg}(\mathrm{L})_{2}\right] \mathrm{Br}_{2}$ complex showed that coordination resulted in ${ }^{13} \mathrm{C}$ carbonyl signal shift to the lower field and total reduction of the $Z$-component according to ${ }^{1} \mathrm{H}$ NMR $N$-methyl signal (Fig. 6B and C).

Thus, the current report elucidates two approaches of freezing $E / Z$ isomeric interconversion within ISBDs that may further find implementation in the medicinal chemistry field. Substitution in the $4^{\text {th }}$ position of the isatin core results in total reduction of $E$-conformation existence, whereas complexation of the isatin Schiff base with $\mathrm{Hg}$ (II) ions stabilizes the ligand $E$ conformation. X-ray powder patterns confirmed the isomeric purity of samples.

I Attempts to isolate Hg(II) complex with ligands II or III didn't succeed.
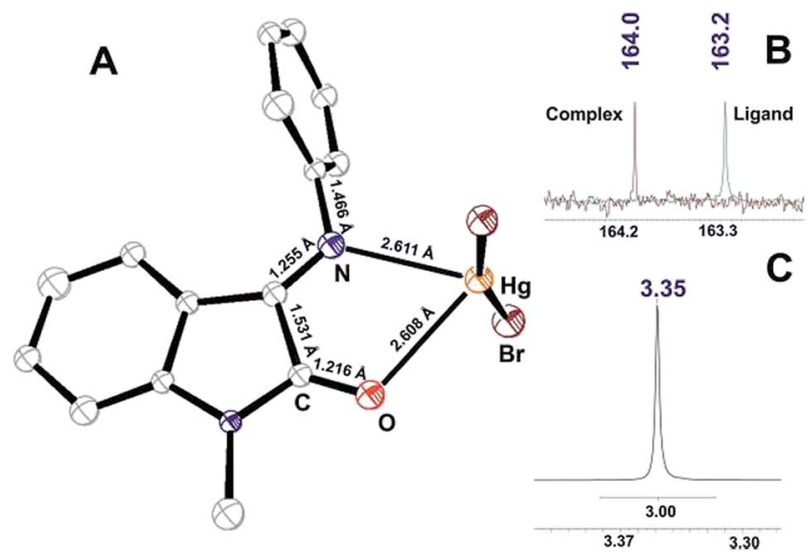

Fig. 6 (A) ORTEP plot of X-ray determined molecular structure of VI; (B) ${ }^{13} \mathrm{C}$ NMR signal for carbonyl of I and $\mathrm{VI} ;(\mathrm{C}){ }^{1} \mathrm{H}$ NMR signal for methyl group of VI.
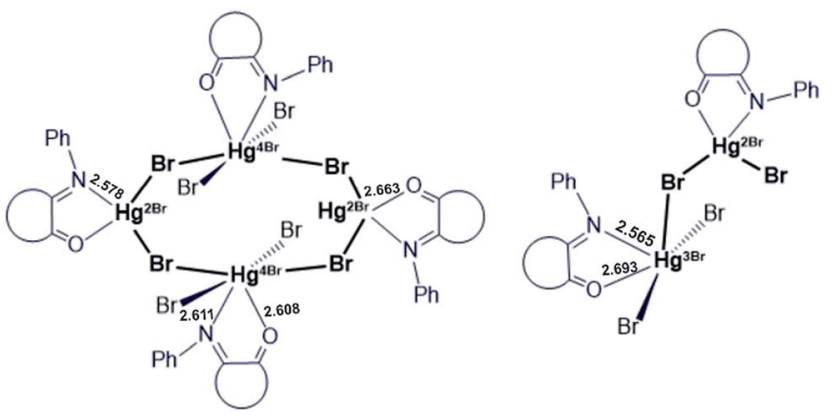

Fig. 7 Schematic representation of $\mathrm{Hg}($ II) - ISBD I supramolecular structures.

It's worthwhile to say that, our ongoing studies show that biogenic 3d-metal ions $\left(\mathrm{Cu}^{2+}, \mathrm{Co}^{2+}, \mathrm{Ni}^{2+}, \mathrm{Mn}^{2+}\right)$ form stable complexes with ISBDs that are more likely to be studied in biochemical assays. Moreover, by the analogy with the homologue iminoquinone complexes catalyst, ${ }^{20}$ the combination of non-innocent ISBDs ligands with RedOx active metals can result in unexpected electrochemical properties of their complexes.

\section{Acknowledgements}

The work was supported by the Ministry of Education and Science of the Russian Federation (14.B25.31013) and by the Russian Foundation for Basic Research (16-34-50250). Physicochemical studies were performed at the Saint-Petersburg State University Centers for Magnetic Resonance, X-ray Diffraction Studies, and Chemical Analysis and Materials Research.

\section{Notes and references}

1 E. G. Gutierrez and A. K. Franz, in Encyclopedia of Reagents for Organic Synthesis, John Wiley \& Sons, Ltd, 2001.

2 N. A. Aslam, S. A. Babu, S. Rani, S. Mahajan, J. Solanki, M. Yasuda and A. Baba, Eur. J. Org. Chem., 2015, 2015, 4168. 
3 T. Sommer, K. Bjerregaard-Andersen, S. M. Simensen, J. K. Jensen, B. Jochimsen, P. J. Riss, M. Etzerodt and J. P. Morth, ACS Chem. Neurosci., 2015, 6, 1353.

4 A. Medvedev, O. Buneeva and V. Glover, Biologics, 2007, 1, 151.

5 L. M. Kara, L. Vine, J. M. Locke and D. Skropeta, Adv. Anticancer Agents Med. Chem., 2013, 2, 254.

6 N. H. Nam, T. L. Huong, D. T. Mai Dung, P. T. Phuong Dung, D. T. Kim Oanh, D. Quyen, L. T. Thao, S. H. Park, K. R. Kim, B. W. Han, J. Yun, J. S. Kang, Y. Kim and S. B. Han, Eur. J. Med. Chem., 2013, 70, 477.

7 Y. Zhou, H.-Y. Zhao, K.-L. Han, Y. Yang, B.-B. Song, Q.-N. Guo, Z.-C. Fan, Y.-M. Zhang, Y.-O. Teng and P. Yu, Biochem. Biophys. Res. Commun., 2014, 450, 1650.

8 H. S. Ibrahim, S. M. Abou-Seri and H. A. Abdel-Aziz, Eur. J. Med. Chem., 2016, 122, 366.

9 S. Sjoli, A. I. Solli, O. Akselsen, Y. Jiang, E. Berg, T. V. Hansen, I. Sylte and J. O. Winberg, Biochim. Biophys. Acta, 2014, 1840, 3162.

10 M. Agamennone, D. S. Belov, A. Laghezza, V. N. Ivanov, A. M. Novoselov, I. A. Andreev, N. K. Ratmanova, A. Altieri, P. Tortorella and A. V. Kurkin, ChemMedChem, 2016, 11, 1892.
11 O. Guzel-Akdemir, A. Akdemir, N. Karal and C. T. Supuran, Org. Biomol. Chem., 2015, 13, 6493.

12 P. Davidovich, V. Aksenova, V. Petrova, D. Tentler, D. Orlova, S. Smirnov, V. Gurzhiy, A. L. Okorokov, A. Garabadzhiu, G. Melino, N. Barlev and V. Tribulovich, ACS Med. Chem. Lett., 2015, 6, 856.

13 A. González, J. Quirante, J. Nieto, M. R. Almeida, M. J. Saraiva, A. Planas, G. Arsequell and G. Valencia, Bioorg. Med. Chem. Lett., 2009, 19, 5270.

14 P. Davidovich, D. Novikova, V. Tribulovich, S. Smirnov, V. Gurzhiy, G. Melino and A. Garabadzhiu, J. Mol. Struct., 2014, 1075, 450.

15 E. J. Barreiro, in Privileged Scaffolds in Medicinal Chemistry: Design, Synthesis, Evaluation, RCS, 2016, pp. 1-15.

16 A. Ercag, S. O. Yildirim, M. Akkurt, M. U. Ozgur and F. W. Heinemann, Chin. Chem. Lett., 2006, 17, 243.

17 R. G. Pearson, J. Am. Chem. Soc., 1963, 85, 3533.

18 P. Saha, A. Saha Roy, T. Weyhermuller and P. Ghosh, Chem. Commun., 2014, 50, 13073.

19 S. Maity, S. Kundu, S. Bera, T. Weyhermüller and P. Ghosh, Eur. J. Inorg. Chem., 2016, 2016, 3691.

20 D. L. J. Broere, R. Plessius and J. I. van der Vlugt, Chem. Soc. Rev., 2015, 44, 6886. 